JURNAL RESPIRASI

JR

Vol. 3 No. 1 Januari 2017

\title{
Peran Masker/Respirator dalam Pencegahan Dampak Kesehatan Paru Akibat Polusi Udara
}

\author{
Haruyuki Dewi Faisal, Agus Dwi Susanto \\ Departemen Pulmonologi dan Ilmu Kedokteran Respirasi, Fakultas Kedokteran Universitas Indonesia, RS. Persahabatan, Jakarta
}

\begin{abstract}
Outdoor air pollution contributed harmful impact to public health. There are several respiratory disorders related to outdoor air pollution such as acute respiratory infection, lung cancer, asthma, chronic obstructive lung disease (COPD) and lung function disorder. Respirator is a personnel protective device which has role in the primary intervention step. Currently exist many types of respirators in industrial setting that have specific function to certain hazard exposure in work process. It is difficult to choose one type of respirator that can be implemented in population setting to protect against all air pollutant content. Therefore, it is relevant choosing one respirator type which has the ability to effectively filtrate one of air pollutant content that is the particulate matter. One respirator type, $N 95$ mask has superiority in term of cost and technical use aspects for protecting particulate matter pollutant. Respirator usage effectivity in population setting is an important subject to find out more.
\end{abstract}

Keywords: health effect, $N 95$ mask, outdoor air pollution, particulate matter, respirator

Correspondence: Haruyuki Dewi Faisal, Departemen Pulmonologi dan Ilmu Kedokteran Respirasi, Fakultas Kedokteran Universitas Indonesia, RS. Persahabatan, Jakarta. E-mail: uqharu@yahoo.com

\section{PENDAHULUAN}

Polusi udara terdiri dari dua macam yaitu polusi udara luar ruangan (outdoor air pollution) dan polusi udara ruangan (indoor air pollution). Polusi udara luar ruangan memberikan gangguan terhadap kesehatan masyarakat. Kematian akibat polusi udara luar ruangan secara global diperkirakan sebanyak 3,7 juta jiwa di tahun 2012 . Sebanyak $14 \%$ dari kematian tersebut terkait dengan penyakit paru obstruksi kronik (PPOK) atau penyakit saluran napas bawah sedangkan $6 \%$ berasal dari kanker paru. International Agency for Research on Cancer (IARC) telah mengemukakan bahwa polusi udara luar ruangan merupakan salah satu faktor karsinogenesis dengan particulate matter sebagai komponen penyebab utama. Wilayah yang banyak terkena dampak polusi udara luar ruangan adalah Pasifik Barat dan Asia Tenggara dengan Indonesia termasuk salah satunya. ${ }^{1-3}$

Bencana alam berupa kebakaran hutan merupakan salah satu komponen penyebab polusi udara luar ruangan. Setiap tahunnya Indonesia mengalami kebakaran hutan yang terjadi pada musim kemarau. Kebakaran hutan besar pernah terjadi di tahun 1997 dan kembali terjadi pada tahun 2015 ini yang meliputi 300.000 hektar lahan di 6 provinsi. Angka peningkatan kasus infeksi saluran napas akut (ISPA) akibat kebakaran hutan pada tahun 2015 ini dilaporkan sebesar 1,8 hingga 3,8 kali dibandingkan tahun sebelumnya. ${ }^{4}, 5$ Pemakaian alat pelindung diri seperti masker debu merupakan salah satu upaya yang dapat dilakukan untuk mengurangi gangguan kesehatan paru akibat polusi udara luar ruangan terkait kebakaran hutan. Polutan yang ditimbulkan kebakaran hutan terdiri dari berbagai jenis komponen zat sehingga sulit untuk memilih satu jenis alat pelindung diri yang dapat berfungsi melindungi dari semua dampak polutan tersebut. Tinjauan pustaka ini akan membahas peran masker/respirator dalam pencegahan gangguan kesehatan akibat polusi udara luar ruangan. Penyebutan polusi udara dalam tinjauan pustaka ini mengacu kepada polusi udara luar ruangan. ${ }^{5,6}$

\section{Kandungan Polutan Udara}

Polutan udara berdasarkan jenisnya dapat dikategorikan menjadi polutan primer dan sekunder. Polutan primer adalah polutan yang berasal langsung dari sumber polutan 

seperti cerobong asap pabrik, pipa knalpot kendaraan bermotor atau kebakaran hutan. Pengukuran kadar polutan primer ini berasal dari data inventaris emisi sumber polutan tersebut. Sedangkan polutan sekunder terbentuk di atmosfer akibat reaksi antara polutan primer dan unsur lain dari alam. Contoh paling populer polutan sekunder adalah ozon $\left(\mathrm{O}_{3}\right)$. Kadar polutan sekunder tidak dapat diukur berdasarkan data inventaris emisi karena model pembentukannya, tetapi dapat diperkirakan dengan rumusan tertentu dengan menentukan kadar volume per satuan waktu di atmosfer. ${ }^{7}$

Berdasarkan sifat fisisnya maka polutan dapat dibagi menjadi polutan gas dan polutan partikel. Polutan gas adalah polutan udara yang berbentuk gas atau uap. Molekul polutan gas dapat langsung memasuki saluran pernapasan. Polutan partikel sering disebut juga dengan particulate matter(PM). Particulate matter merupakan polutan utama pemberi dampak pada kesehatan. Polutan ini terdiri atas unsur sulfat, nitrat, amonia, natrium klorida, karbon debu mineral dan air yang tersuspensi dalam fase cairan dan padat di udara. Jenis PM sebagai indikator polutan udara dapat dibagi menjadi $\mathrm{PM}_{10}$ dan $\mathrm{PM}_{2,5}$. Ukuran diameter $\mathrm{PM}_{10}$ adalah 2,5-10 $\mu \mathrm{m}$ sedangkan $\mathrm{PM}_{2,5}$ adalah $<2,5 \mu \mathrm{m}$. Dalam gambar 1 dapat dilihat perbandingan ukuran PM dan unsur lain sebagai pembanding. ${ }^{7}$

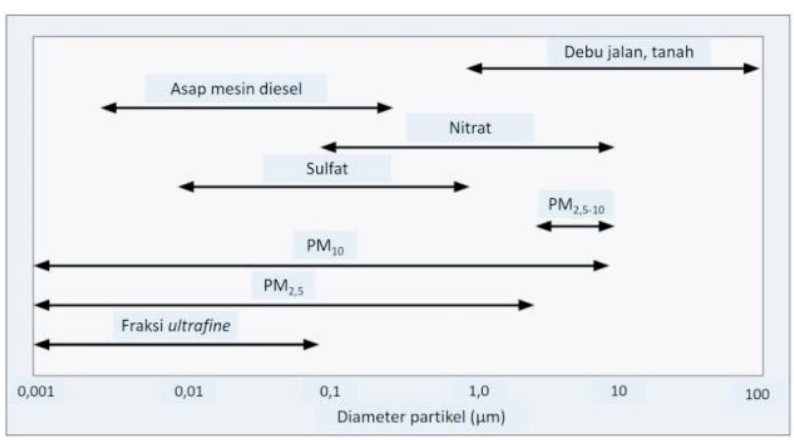

Gambar 1. Ukuran diameter PM dan unsur lain ${ }^{7}$
Polutan primer terdiri atas sulfur dioksida $\left(\mathrm{SO}_{2}\right)$, nitrogen oksida $(\mathrm{NO})$, karbon monoksida $(\mathrm{CO})$, volatile organic compound (VOC), partikel karbon dan partikel nonkarbon. Pada gambar 1 dijelaskan sumber polutan primer dan mekanisme pelepasannya ke atmosfer. Ozon terbentuk akibat reaksi kimia yang berbeda-beda disesuaikan dengan ketinggian atmosfer. World Health Organization (WHO) mengeluarkan panduan mengenai kualitas udara bersih dengan menilai beberapa kandungan polutan di dalamnya. Kandungan polutan yang biasa dijadikan indikator kualitas udara bersih adalah $\mathrm{PM}, \mathrm{O}_{3}$, nitrogen dioksida $\left(\mathrm{NO}_{2}\right)$ dan $\mathrm{SO}_{2}{ }^{7}$

Batasan nilai polutan telah direkomendasikan oleh WHO berdasarkan kandungan harian, tahunan atau periode waktu tertentu. Kandungan tersebut menunjukkan satuan berat dalam mikrogram $(\mu \mathrm{g})$ per satuan volume meter kubik $\left(\mathrm{m}^{3}\right)$. Batasan kadar empat parameter polutan udara yang biasa dijadikan acuan WHO dalam menilai tingkat keparahan polusi udara dijelaskan dalam tabel 2. Batasan nilai polutan yang dibuat oleh WHO ini bersifat global. Berdasarkan komponen polutan tersebut, tiap negara memadukannya dan mengkategorikan tingkat keparahan polusi agar dapat diketahui masyarakat. ${ }^{1}$

Setiap negara memiliki sistem pelaporan kualitas udara kepada masyarakatnya masing-masing. Indonesia memakai sistem pelaporan indeks standar pencemaran udara (ISPU). Negara lain memiliki sistem pelaporan berbeda, contohnya Inggris dan Amerika Serikat memakai air quality index (AQI), Kanada dengan air quality health index (AQHI), Singapura memakai pollutant standar index (PSI) sementara Malaysia melaporkan dengan sistem air pollutant index (API). Pada prinsipnya masing-masing negara memakai komponen penilaian yang hampir sama. Perbedaan terletak pada rentang nilai parameter dan penamaan kategori tingkat keparahan polusi udara. $8,9,19,11,12$

Berdasarkan surat keputusan kepala Badan Pengendalian Dampak Lingkungan (Bapedal) KEP107/KABAPEDAL/11/1997, parameter polutan yang

Tabel 1. Polutan primer dan sumber emisi ${ }^{7}$

\begin{tabular}{|c|c|c|}
\hline Nama polutan & Sumber emisi & Mekanisme \\
\hline Sulfur dioksida & $\begin{array}{l}\text { Bahan bakar mengandung sulfur (batu bara } \\
\text { dan minyak bumi) }\end{array}$ & $\begin{array}{l}\text { Sulfur berubah menjadi sulfur dioksida dalam } \\
\text { proses pembakaran bahan bakar fosil }\end{array}$ \\
\hline Nitrogen oksida & $\begin{array}{l}\text { Batu bara banyak kandungan nitrogen dan } \\
\text { sedikit minyak bumi }\end{array}$ & $\begin{array}{l}\text { Nitrogen berubah menjadi nitrogen oksida saat } \\
\text { pembakaran bahan bakar }\end{array}$ \\
\hline Karbon monoksida & Bahan bakar mengandung karbon & $\begin{array}{l}\text { Pembakaran tidak sempurna, misalnya proses } \\
\text { pembakaran pada kendaraan bermotor }\end{array}$ \\
\hline Volatile organic compound & $\begin{array}{l}\text { Uap mengandung rantai hidrokarbon, } \\
\text { oksigenat, halogenat di atmosfer }\end{array}$ & $\begin{array}{l}\text { Evaporasi bahan bakar cair (benzena dari tanki } \\
\text { kendaraan bermotor) }\end{array}$ \\
\hline Partikel karbon & Bahan bakar fosil, biomas & Pembakaran bahan bakar fosil, biomas \\
\hline Partikel non karbon & $\begin{array}{l}\text { Debu terbang berasal dari batu bara, } \\
\text { penambangan mineral, tanah }\end{array}$ & $\begin{array}{l}\text { Debu yang berasal dari pembakaran batu bara, } \\
\text { proses penambangan, tanah yang terbawa angin }\end{array}$ \\
\hline
\end{tabular}


Tabel 2. Batasan kadar parameter polutan udara ${ }^{1}$

\begin{tabular}{lccccc}
\hline \multirow{2}{*}{ Nama polutan } & \multicolumn{5}{c}{ Kadar $\left(\boldsymbol{\mu g} / \mathbf{m}^{3}\right)$} \\
\cline { 2 - 6 } & Harian & Tahunan & $\mathbf{1}$ jam & $\mathbf{8}$ jam & $\mathbf{1 0}$ menit \\
\hline PM10 & 50 & 20 & - & - & - \\
PM2,5 & 25 & 10 & - & - & - \\
Ozon & - & - & - & 100 & - \\
Nitrogen oksida & - & 40 & - & - & 500 \\
Sulfur dioksida & 20 & - & - & - \\
\hline
\end{tabular}

Tabel 3. Indeks, kategori dan warna ISPU ${ }^{14}$

\begin{tabular}{lcc}
\hline \multicolumn{1}{c}{ Indeks } & Kategori & Warna \\
\hline $1-50$ & Baik & Hijau \\
$51-100$ & Sedang & Biru \\
$101-199$ & Tidak sehat & Kuning \\
$200-299$ & Sangat tidak sehat & Merah \\
$300-$ lebih & Berbahaya & Hitam \\
\hline
\end{tabular}

dinilai dalam ISPU adalah $\mathrm{PM}_{10}, \mathrm{SO}_{2}, \mathrm{CO}, \mathrm{O}_{3}$ dan $\mathrm{NO}_{2}$. Masing-masing parameter diukur dalam kurun waktu tertentu. Rentang nilai ISPU dilaporkan dengan berbagai macam warna sesuai tingkat keparahan. Terkait dengan kebakaran hutan, kolaborasi instansi pemerintah seperti Kementerian Lingkungan Hidup dan Kehutanan, Departemen Kesehatan dan Badan Meteorologi dan Geofisika secara berkesinambungan melaporkan situasi terakhir dan memberikan rekomendasi kepada masyarakat dalam menyikapi tingkat keparahan polusi udara tersebut. Tabel 3 memberikan informasi mengenai ISPU. ${ }^{13-15}$

\section{Dampak Polusi Udara terhadap Kesehatan Paru}

Beberapa bukti mengungkapkan dampak polusi udara terhadap kesehatan paru, baik penelitian epidemiologi, pajanan klinis terhadap manusia, pajanan lingkungan dan

toksikologi pada hewan coba. ${ }^{16}$ Sementara di sisi lain

Marino mengemukakan bahwa masih diperlukan bukti lagi untuk menguatkan hubungan antara polusi udara dengan beberapa gangguan penyakit paru seperti ISPA, penurunan faal paru, PPOK, kanker paru dan asma. ${ }^{17}$ Ukuran diameter PM diduga menjadi faktor memberatnya dampak polusi udara terhadap kesehatan. Semakin kecil ukuran PM maka semakin tinggi efek penetrasinya hingga dapat mempengaruhi saluran napas bawah. ${ }^{18}$ Gambar memperlihatkan jangkauan PM terhadap saluran napas. ${ }^{19}$

Sebuah ulasan sistematik di Cina menganalisis dampak polusi $\mathrm{PM}_{10}$ dan $\mathrm{PM}_{2,5}$ terhadap mortalitas dan gangguan

kesehatan paru. Terdapat hubungan bermakna antara peningkatan nilai $\mathrm{PM}_{10}$ sebesar $10 \mu \mathrm{g} / \mathrm{m}^{3}$ dengan mortalitas penyakit paru, namun tidak terdapat hubungan bermakna peningkatan $\mathrm{PM}_{2,5}$ sebesar $10 \mu \mathrm{g} / \mathrm{m}^{3}$ dengan mortalitas akibat penyakit paru. ${ }^{20}$ Studi kohort restrospektif selama 12

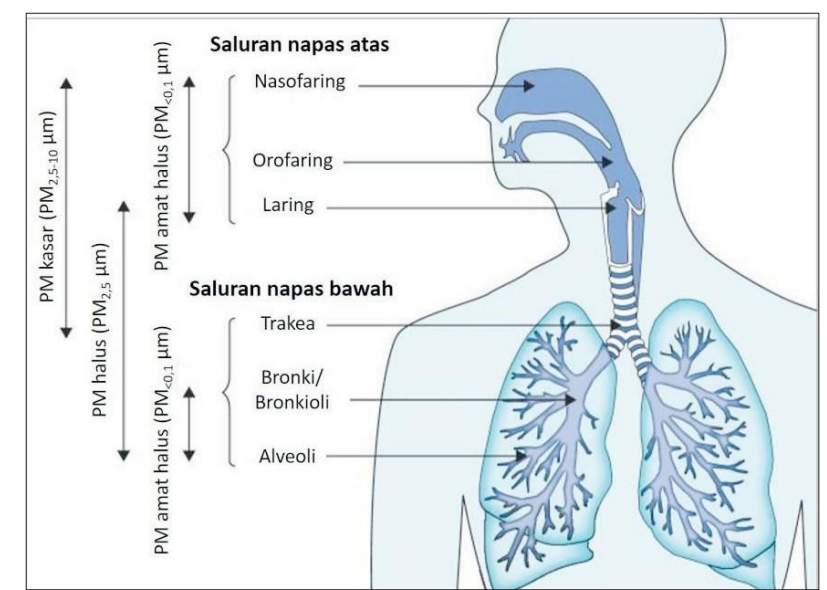

Gambar 2. Lokasi deposisi particulate matter. ${ }^{19}$

tahun di Shenynang, Cina, melaporkan bahwa $\mathrm{PM}_{10}$ dan gas $\mathrm{NO}_{2}$ sangat berhubungan dengan mortalitas penyakit paru, sedangkan tidak terdapat hubungan pada gas $\mathrm{SO}_{2} \cdot{ }^{21}$

Kebakaran hutan berkontribusi dalam peningkatan parameter polusi udara. Dampak yang ditimbulkan dapat memengaruhi area yang jauh dari pusat kebakaran hutan. Unsur polutan yang ditimbulkan kebakaran hutan antara lain adalah PM, karbon monoksida, uap merkuri, unsur kimia pembentuk ozon dan VOC. ${ }^{22}$ Komponen utama polutan akibat kebakaran yang patut diwaspadai adalah $\mathrm{PM}_{2,5}$. Tingkat polusi udara pada area 100 mil dari titik api ditemukan 5-15 kali lebih buruk dari batas normal serta 2-3 kali lebih buruk bila dibandingkan kadar polutan pada saat terburuk bukan akibat kebakaran hutan. ${ }^{23}$

\section{Masker/Respirator sebagai Pelindung Saluran Napas Masker Prosedur}

Masker prosedur adalah nama lain dari masker bedah. Jenis masker ini tidak memiliki kemampuan menutupi hidung dan mulut dengan sempurna karena terdapat celah di keempat sisi masker tersebut. Tujuan pemakaian masker prosedur adalah untuk menyaring udara yang keluar dari mulut atau hidung pemakai. Masker prosedur tidak berbeda bermakna dengan masker kertas yang dipakai pada industri pengamplasan yang bertujuan menyaring partikel besar (debu amplas). Masker prosedur tidak termasuk dalam kategori respirator yang tersertifikasi lembaga seperti 
National Institute for Occupational Safety and Health (NIOSH) di Amerika Serikat maupun European Committee for Standardization/Comité Européen de Normalisation (CEN) di Eropa. ${ }^{24}$

\section{Respirator}

Respirator merupakan suatu alat pelindung diri yang dipakai di wajah, setidaknya meliputi hidung dan mulut. Pelindung diri ini berfungsi untuk mengurangi risiko bahaya partikel di udara, gas dan uap. Pemakai respirator haruslah memahami cara pemakaiannya agar respirator dapat berfungsi secara optimal. Setiap pemakai respirator harus menjalani pelatihan tentang bagaimana cara memakai alat tersebut. Selain itu terdapat pula suatu upaya memastikan pemakai respirator telah memakai dengan benar. Upaya ini disebut dengan fit testing. Jenis fit testing ada dua yaitu kualitatif dan kuantitatif. Secara singkat prosedur fit testing adalah pemakaian respirator, kemudian diberikan pajanan tertentu dan dilihat apakah ada kebocoran atau tidak. Respirator dapat dibagi berdasarkan cara pemakaian dan mekanisme kerja. ${ }^{25,26}$

1. Klasifikasi berdasarkan cara pemakaian

Pembagian jenis respirator dapat diklasifikasikan berdasarkan cara pemakaian yaitu respirator pakai ketat (tight fitting) dan longgar (loose fitting). Respirator pakai ketat adalah respirator yang cara pakainya secara ketat menutupi setengah wajah ataupun seluruh wajah. Tepi respirator berfungsi sebagai pembatas kedap dengan udara luar. Sedangkan respirator pakai longgar berupa helm atau kerudung yang menutupi seluruh kepala. ${ }^{27}$ Gambar 3 menampilkan jenis respirator pakai ketat dan longgar. ${ }^{28}$

2. Klasifikasi berdasarkan mekanisme kerja

Berdasarkan mekanisme kerja maka respirator dibagi menjadi dua yaitu respirator pemurni udara (air purifying) dan pemasok udara (air supplying). Mekanisme respirator pemurni udara bekerja dengan cara menghilangkan kontaminan dari udara, salah satu contoh respirator ini yang banyak dipakai adalah N95. Sedangkan respirator pemasok udara menyediakan sumber udara bersih dan sebagai contoh sumber udara berasal dari tabung berisi oksigen terikat di punggung pemakai. Masing-masing kelompok pembagian respirator berdasarkan mekanisme kerja ini memiliki jenis-jenis sebagai berikut: ${ }^{26,29,30}$
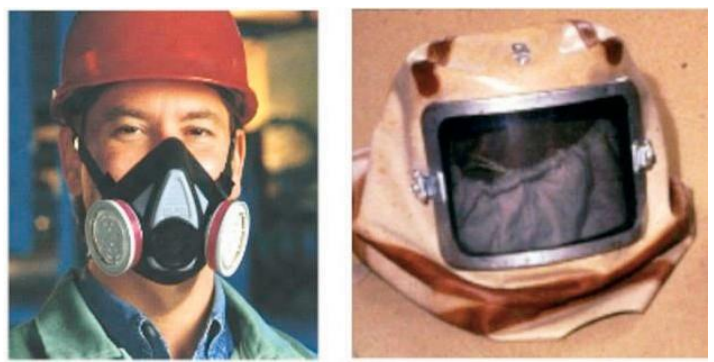

Gambar 3. Jenis respirator pakai ketat (kiri) dan longgar $(\text { kanan })^{28}$

\section{a. Pemurni udara}

Respirator pemurni udara terdiri atas powered air purifying respirator (PAPR) dan non-powered air purifying respirator (non-PAPR). Jenis yang pertama disebut dengan istilah powered karena menggunakan daya listrik berupa baterai untuk menciptakan tekanan positif dalam masker dengan cara mengambil, menyaring dan kemudian mengalirkan udara luar ke dalam bagian masker. Jenis non-PAPR tidak memiliki daya listrik untuk menyaring udara dan tekanan yang ada dalam masker adalah tekanan negatif. Jenis non-PAPR terdiri atas filtering piece, full facepiece, half mask, quarter mask dan mouth bit. Pembagian jenis ini dapat dilihat dalam Gambar 4. ${ }^{23}, 28$

Respirator pemurni udara menyaring partikel dan gas/uap yang didapat akibat pengaruh di lingkungan kerja dan akibat polusi udara. Penyaringan partikel mengandalkan diameter pori untuk menyaring partikel-partikel yang berukuran lebih besar. Jenis respirator pemurni udara yang beredar di pasaran misalnya masker sekali pakai N95 (filtering piece) dan respirator elastomer (full facepiece, half mask, quarter mask, mouth bit) yang dapat dipakai berulang dengan cara mengganti bagian penyaringnya saja, sedangkan bagian masker yang terbuat dari bahan elastomer dapat dicuci. Pada respirator elastomer, penyaring gas/uap pemurni udara dilakukan dengan menggunakan cartridge atau canister yang berisi bahan adsorben dan absorben seperti karbon atau bahan spesifik lain yang dapat melindungi dari gas asam, uap organik maupun kontaminan tertentu seperti uap merkuri. ${ }^{31}$

Terdapat beberapa parameter untuk mengetahui karakteristik suatu respirator. Karakteristik ini diinformasikan dalam bentuk kode huruf dan angka. Huruf $\mathrm{N}$ berarti respirator tersebut non-oil resistance atau tidak tahan terhadap uap minyak sehingga harus dipakai di lingkungan kerja bebas minyak. Kode $\mathrm{R}$ artinya somewhat oil-resistance yang tahan terhadap uap minyak hanya dalam satu giliran jadwal kerja. Kode $\mathrm{P}$ yang berarti oil-proof yang dapat dipakai di area kerja berminyak dalam jangka waktu lebih

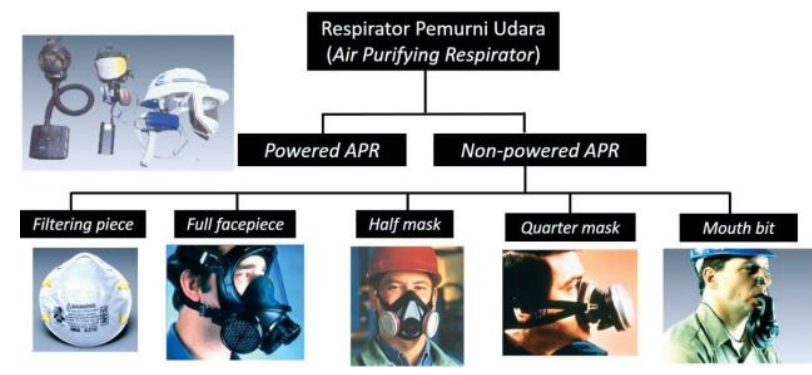

Gambar 4. Pembagian jenis respirator pemurni udara ${ }^{24,28}$ 
dari satu giliran jadwal kerja. ${ }^{32}$ Angka-angka yang mengikuti kode huruf ini adalah 95, 99, dan 100. Angka ini berarti jumlah persentase partikel udara yang dapat disaring berdasarkan uji laboratorium yang dilakukan oleh NIOSH, berturut-turut sebagai berikut $95 \%, 99 \%$ dan $99,97 \% .{ }^{33}$

Masker N95 adalah bagian dari respirator pemurni udara jenis filtering piece. Masker jenis ini merupakan suatu produk yang dapat menyaring PM dengan ukuran 0,3 $\mu \mathrm{m}$ sebesar $95 \%$. Dari segi harga maupun teknis pemakaian, masker N95 memiliki kelebihan dibandingkan masker pemurni udara jenis lain dalam menghadapi polusi udara. Masker N95 berbeda dengan masker prosedur yang kemampuan filtrasinya tidak tersertifikasi oleh NIOSH. Gambar 5 adalah masker N95 beserta keterangan spesifikasinya. ${ }^{24,33}$

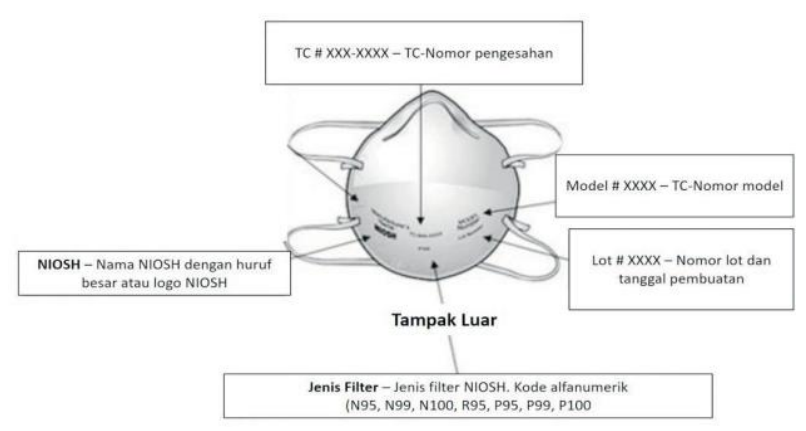

Gambar 5. Masker N95 beserta informasi spesifikasinya. ${ }^{33}$

\section{b. Pemasok udara}

Berdasarkan sumbernya, respirator pemasok udara dapat dibedakan atas self-containing breathing apparatus (SCBA), airline respirator dan SCBA kombinasi. Respirator jenis SCBA sumber pemasok udara berasal dari tabung berisi oksigen terikat di punggung pemakai sehingga membuat leluasa berpindah ke mana saja. Respirator jenis Airline respirator bersumber dari suatu tabung oksigen tak

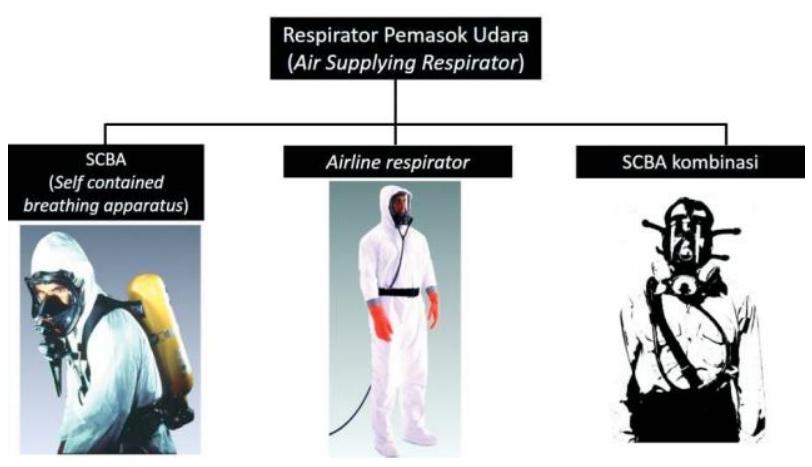

Gambar 6. Pembagian jenis respirator pemasok udara. ${ }^{28,29}$

bergerak atau kompresor udara yang terhubung dengan sebuah selang, sehingga pemakaiannya terbatas hanya di sekitar sumber udara berada tidak seperti SCBA. Respirator jenis SCBA kombinasi, contohnya SCBA yang juga dilengkapi dengan respirator pemurni udara. Perbedaan mengenai jenis respirator tersebut dijelaskan pada Gambar 6. ${ }^{28,29}$

\section{Assigned Protection Factors}

Assigned Protection Factors (APF) merupakah suatu parameter angka yang menginformasikan kemampuan suatu respirator melindungi pemakai.

\section{Mekanisme Penyaringan (Filtrasi)}

Penyaringan partikulat memiliki dua tipe: absolut dan nonabsolut. Penyaring absolut menggunakan sekat untuk membuang partikel dari udara dengan menyingkirkan partikel yang ukurannya lebih besar dari pori-pori sekat. Kebanyakan respirator besifat nonabsolut, artinya respirator mengandung pori yang ukurannya lebih besar dibanding partikel yang seharusnya dibuang. Pembuangan partikel menggunakan kombinasi dari penangkap tahanan (interception capture), penangkap pengendapan (sedimentation capture), penangkap impaksi inersial (inertial impaction capture), penangkap difusi (diffusion

Tabel 4. Jenis respirator dan nilai $\mathrm{APF}^{34}$

\begin{tabular}{|c|c|c|c|c|c|}
\hline Jenis respirator & Masker 1/4 & Masker 1/2 & Masker Penuh & Helm/Kerudung & $\begin{array}{c}\text { Loose-fitting } \\
\text { face piece }\end{array}$ \\
\hline Respirator pemurni udara & 5 & $10^{3}$ & 50 & - & - \\
\hline $\begin{array}{l}\text { Respirator pemurni udara } \\
\text { dengan daya listrik (PAPR) }\end{array}$ & - & 50 & 1.000 & $25 / 1.000^{4}$ & 25 \\
\hline \multicolumn{6}{|l|}{ Respirator pemasok udara } \\
\hline Modus permintaan & - & 10 & 50 & - & - \\
\hline Modus aliran kontinyu & - & 50 & 1.000 & $25 / 1.000^{4}$ & 25 \\
\hline Modus tekanan & - & 50 & 1.000 & - & - \\
\hline \multicolumn{6}{|l|}{ SCBA } \\
\hline Modus permintaan & - & 10 & 50 & 50 & - \\
\hline Modus tekanan & - & - & 10.000 & 10.000 & - \\
\hline
\end{tabular}


capture) dan penangkap elektrostatik (electrostatic capture). Kombinasi tepat dari mekanisme filtrasi bergantung pada laju aliran di filter dan ukuran partikel. Partikel yang lebih besar dan berat akan dibuang melalui penangkap inersial dan tahanan, partikel besar dan ringan akan dibuang melalui penangkap difusi dan tahanan dan partikel yang sangat kecil akan dibuang melalui penangkap difusi. ${ }^{35}$

a.

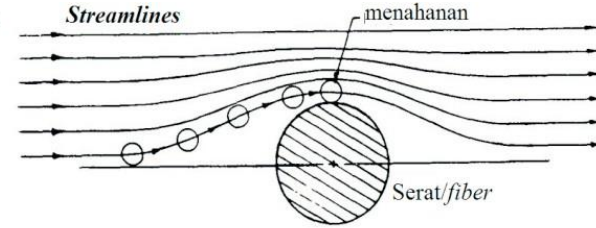

b.

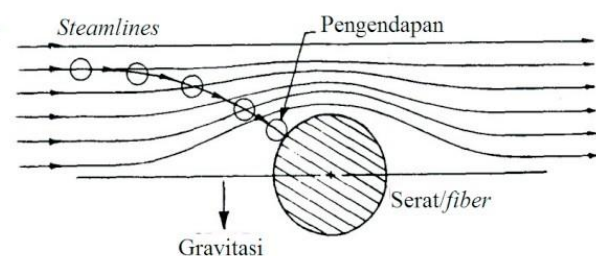

c.

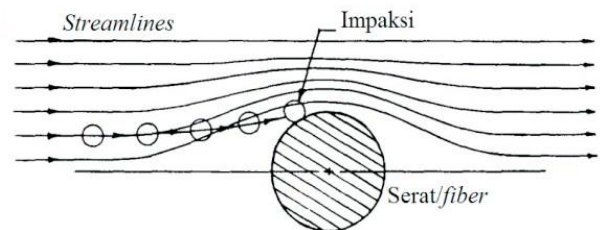

Gambar 7. Mekanisme penyaringan; a. mekanisme penangkap tahanan (interception capture), b. mekanisme penangkap pengendapan (sedimentation capture), c. mekanisme penangkap impaksi (impaction capture $)^{35}$

\section{Peran Masker/Respirator dalam Mencegah Gangguan Kesehatan Paru Akibat Polusi Udara}

Prinsip tiga langkah pencegahan penyakit yaitu pencegahan primer, sekunder dan tersier. Pemakaian respirator termasuk dalam langkah pencegahan primer sebagai bagian dari pemakaian alat pelindung diri (APD). ${ }^{36}$ Pembahasan sebelumnya menjelaskan bahwa kandungan polutan udara terdiri dari berbagai macam jenis, sehingga masyarakat sulit memilih jenis respirator yang dapat melindungi diri dari dampak seluruh polutan tersebut. Usaha perlindungan diri dari dampak polusi udara berfokus kepada proteksi terhadap polutan PM merupakan usaha yang relevan. ${ }^{6}$

Pemakaian APD seperti masker/respirator merupakan upaya untuk mengurangi dampak kesehatan polusi udara. Beberapa penelitian di populasi sering memakai jenis masker atau respirator seperti masker kain, masker bedah dan N95. Penelitian mengenai faal paru pada petugas polisi lalu lintas di Jakarta mengemukakan bahwa tidak terdapat hubungan bermakna antar kebiasaan pemakaian masker dengan gangguan faal paru. Dalam penelitian ini kebiasan pemakaian masker secara baik hanya $9,1 \%$, dan sedang sebesar 25,6\% serta buruk sebesar $62,3 \%$. Tidak disebutkan secara jelas jenis masker yang digunakan. ${ }^{37}$ Penelitian sejenis pada polisi lalu lintas di Thailand didapatkan terdapat hubungan bermakna antara pemakaian masker dengan gangguan faal paru. Pemakaian masker/respirator tidak menurunkan faal paru. ${ }^{38}$

Sebuah penelitian di Korea mencoba mengetahui efektivitas kerja beberapa jenis masker yaitu masker anti yellow sand (setara dengan N95), masker karantina (setara dengan N95), masker prosedur, masker biasa dan sapu tangan. Dalam penelitian ini didapatkan daya tembus maksimal sebesar 6\% pada masker anti yellow sand dan masker karantina. Sedangkan masker prosedur, biasa dan sapu tangan sedikit memberikan proteksi. ${ }^{39}$ Penelitian di India menjelaskan bahwa tidak terdapat hubungan bermakna antar nilai arus puncak respirasi (APE) pada polisi yang memakai masker dibandingkan dengan yang tidak memakai masker. Pada penelitian ini jenis masker yang dipakai hanya disebut sebagai breathing mask. ${ }^{40}$

Penelitian di Cina terkait dengan masker N95 membuktikan bahwa jenis masker ini mampu memberikan perbedaan signifikan dalam menyaring $\mathrm{PM}_{2,5}$.

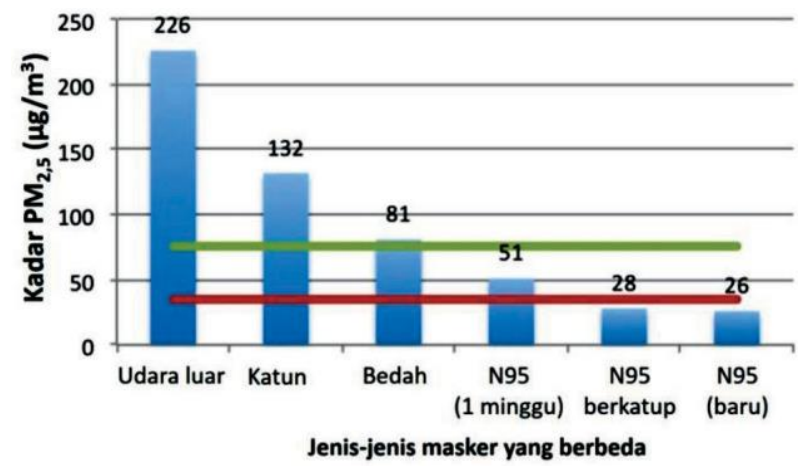

Gambar 8. Perbandingan kemampuan filtrasi masker N95 terhadap $\mathrm{PM}_{2,5} \cdot{ }^{41}$

Penelitian di California pada tahun 1999 tentang kebakaran hutan dan dampak terhadap kesehatan menyatakan bahwa masker N95 maupun masker bedah tidak mampu melindungi masyarakat dari gangguan saluran napas bagian bawah. Hal ini disebabkan beberapa faktor yaitu lama pajanan di luar dan tidak cukupnya fit testing. Selain itu diduga masyarakat menjadi cenderung ingin berlama di luar rumah karena merasa telah aman memakai masker. Dalam penelitian lain oleh Kunzil dkk saat kebakaran di California Selatan tahun 2003 ditemukan bahwa terjadi penurunan gejala pada kelompok pemakai masker. Kebakaran hutan di Indonesia pada tahun 1997 memberikan data terkait rekomendasi skala nasional pemakaian masker. Salah satu faktor yaitu tidak seringnya memakai masker berhubungan dengan eksaserbasi gejala respirasi. ${ }^{42}$

Rekomendasi pemakaian masker N95 harus memperhatikan beberapa faktor. Fit testing merupakan prasyarat utama agar respirator dapat bekerja secara 
optimal. Permasalahan di lapangan berupa kurangnya edukasi dapat membuat masyarakat tidak memakai masker dengan benar. Kelompok masyarakat juga perlu dipilih mana yang direkomendasikan untuk pemakaian respirator dan mana yang tidak. Anak-anak tidak direkomendasikan memakai respirator. Perempuan hamil, orang tua dan orang dengan gangguan paru kronik memerlukan penilaian lebih lanjut dalam rekomendasi pemakaian respirator. Walau terdapat keterbatasan tetapi pemakaian respirator dapat memberikan proteksi hingga tingkat tertentu terhadap dampak polusi udara akibat kebakaran hutan. ${ }^{24}$

\section{KESIMPULAN}

1. Kandungan polusi udara bersifat bahaya terhadap kesehatan masyarakat.

2. Respirator sebagai alat pelindung diri saluran napas terdiri dari berbagi macam jenis sesuai dengan kebutuhan pajanan yang dihadapi.

3. Penggunaan masker/respirator seperti masker bedah dan N95 bertujuan untuk mengurangi dampak polusi udara terhadap kesehatan paru akibat polusi udara.

4. Masker prosedur hanya sedikit memberi proteksi.

5. Masker N95 terbukti menurunkan angka penyakit paru pada kebakaran hutan.

\section{DAFTAR PUSTAKA}

1. World Health Organizaion. Ambient (outdoor) air quality and healthFact sheet [Online]. 2014. [Cited 2015 Nov 2] Available from: http:// www.who.int/mediacentre/factsheets/fs313/en/.

2. Myers I, Maynard R. Polluted air-outdoors and indoors. Occup med. 2005; 55(6): 432-8.

3. Loomis D, Huang W, Chen G. The International Agency for Research on Cancer (IARC) evaluation of the carcinogenicity of outdoor air pollution: focus on China. Chin J Cancer. 2014; 33(4): 189-96.

4. Kementrian kesehatan Republik Indonesia. Tanggap Darurat Terhadap Kabut Asap [Online]. 2015. [Cited 2015 Nov 2]. Available from: http://www.depkes.go.id/article/view/15101900002/tanggap-daruratterhadap-kabut-asap.html.

5. Yoga AT. Penilaian polusi udara. J Respir Indo. 1999; 1: 4-10.

6. Sbihi H. Evidence Review: Using masks to protect public health during wildfire smoke events. Vancouver: Environmental Health Services; 2014. p. 5.

7. Samet, JM. Brauer M. Schlesinger R. Source of air pollution. In: Air Quality Guidelines - Global Update. Copenhagen: WHO; 2006. p. 9-30.

8. Departement of Environment Malaysia. A Guide To Air Pollutant Index $\ln$ Malaysia (API). $4^{\text {th }}$ ed. Kuala Lumpur: Departement of Environment Malaysia; 2000. p. 4-6.

9. National Environment Agency. FAQs on PSI (Pollutant standard index) [Online]. 2014. [Cited 2015 Nov 2]. Available from: http:// www.nea.gov.sg/anti-pollution-radiation-protection/air-pollutioncontrol/psi/faqs-on-psi\#.

10. Ayres JG. Review of the Air Quality Index: Considerations and Approaches Taken. In: Holgate S, editor. Review of the UK Air Quality Index. London: Health Protection Agency for the Committee on the Medical Effects of Air; 2011.p. 14-19.

11. Mintz D. Technical Assistance Document for the Reporting of Daily Air Quality-the Air Quality Index (AQI). North Carolina: U.S. Environmental Protection Agency; 2013.p. 1-11.
12. Government of Canada. The new Air quality health index: How air pollution affects your health Fact sheet [Online]. 2014. [Cited 2015 Nov 3]. Available from: http://publications.gc.ca/site/eng/home. html.

13. Kementrian lingkungan hidup dan kehutanan. Indeksi kualitas udara [Online]. 2014. [Cited 2015 Nov 3]. Availablefrom: http://iku.menlhk. go.id/.

14. Badanpengendalian dampak lingkungan. Pedomanteknisperhitungan dan pelaporan serta informasi indeks standar pencemarudara [Online]. 1998. [Cited 2015 Nov 3. Available from: http://www.cetsuii.org/ BML/Udara/ISPU/ISPU\%20(Indeks\%20Standar\%20Pencemar\%20 Udara).htm.

15. Badan Meteorologi, Klimatologi dan Geofisika. Informasi Partikulat (PM10) [Online]. 2015. [Cited 2015 Nov 3]. Available from: http://www.bmkg.go.id/BMKG_Pusat/Kualitas_Udara/Informasi_ Partikulat.bmkg.

16. Committee of the Environmental and Occupational Health Assembly of the American Thoracic Society. Health effects of outdoor air pollution. Am J Respir Crit Care Med. 1996; 153(1): 3-50.

17. Marino E, Caruso M, Campagna D, Polosa R. Impact of air quality on lung health: myth or reality? Ther Adv Chronic Dis. 2015; 6(5): 286-98.

18. Kim KH, Kabir E, Kabir S. A review on the human health impact of airborne particulate matter. Environ Int. 2015; 74: 136-43.

19. Guarnieri M, Balmes JR. Outdoor air pollution and asthma. The Lancet. 2014; 383(9928): 1581-92.

20. Lu F, Xu D, Cheng Y, Dong S, Guo C, Jiang X, et al. Systematic review and meta-analysis of the adverse health effects of ambient PM 2.5 and PM 10 pollution in the Chinese population. Environmental research. 2015; 136: 196-204.

21. Dong GH, Zhang P, Sun B, Zhang L, Chen X, Ma N, et al. Long-term exposure to ambient air pollution and respiratory disease mortality in Shenyang, China: a 12-year population-based retrospective cohort study. Respiration. 2012; 84(5): 360-8.

22 British Colombia. How Forest Fires Affect Air Quality [Online]. 2007. [Cited 2015 Nov 3]. Available from: http://www.bcairquality. ca/topics/forest-fires-air-quality.html.

23. Kenward A, Adams-Smith D, Raja U. Wildfires and air pollution-the hidden health hazards of climate change. New Jersey: Climate central; 2013. p. 11.

24. Sbihi H. Types of masks. In: Elliott C, Rideout K, ed. Evidence Review: Using masks to protect public health during wildfire smoke events. Vancouver: Environmental Health Services; 2014.p. 3-4.

25. CDC. Respirator Trusted-Source Information-Section 3: Ancillary Respirator Information [Online]. 2015. [Cited 2015 Nov 7]. Available from: http://www.cdc.gov/niosh/nppt1/topics/respirators/disp_part/ respsource3basic.html\#b.

26. Occupational Safety and Health Administration. Respiratory Protection. Washington DC: U.S. Department of Labor; 2002. p. 1-3.

27. Bollinger NJ, Schutz RH. Fit testing procedures. In: NIOSH Guide to Industrial Respiratory Protection. Ohio: National Institute for Occupational Safey and Health; 1987. p. 145-70.

28. Occupational Safety and Health Administration. OSHA's Respiratory Protection Standard 29 CFR 1910134 [Online]. 2015. [Cited 2015 Nov 12]. Available from: https://www.osha.gov/dte/library/ respirators/presentation/.

29. Bollinger NJ, Schutz RH. Types of respirators. In: NIOSH Guide to Industrial Respiratory Protection. Ohio: National Institute for Occupational Safey and Health; 1987.p.3-54.

30. Occupational Safety and Health Administration. OSHA Technical Manual- Section VIII Chapter 2: Respiratory Protection [Online]. 2015. [Cited 2015 Nov 12]. Available from: https://www.osha.gov/ dts/osta/otm/otm_viii/otm_viii_2.html.

31. Sargent EV, Gallo F. Use of personal protective equipment for respiratory protection. ILAR Journal. 2003; 44(1): 52-6.

32 Occupational Safety and Health Administration. General Respiratory Protection Guidance for Employers and Workers. Washington DC: U.S. Department of Labor; 2015. p. 1-5. 
33. Centers for Disease Control and Prevention. NIOSH Approved Particulate Filtering Facepiece Respirators [Online]. 2015. [Cited 2015 Nov 12]. Available from: http://www.cdc.gov/niosh/npptl/ topics/respirators/disp_part/.

34. Occupational Safety and Health Administration. Assigned Protection Factors for the Revised Respiratory Protection Standard. Washington DC: U.S. Department of Labor; 2009. p. 10-4.

35. Japuntich DA. Respiratory particulate filtration. J Ind Soc Respir Prot. 1984; 2(1): 137-69.

36. Henneberger PK, Redlich CA, Callahan DB, Harber P, Lemiere C, Martin J, et al. An official american thoracic society statement: work-exacerbated asthma. Am J Respir Crit Care Med. 2011; 184(3); 368-78.

37. Ginting M, Yunus F, Antariksa B. Faal paru pada polisi lalu lintas jakarta pusat dan faktor-faktor yang mempengaruhi. J Respir Indo. 2015; 35(2): 97-106.

38. Wongsurakiat P, Maranetra K, Nana A, Naruman C, Aksornint M, Chalermsanyakorn T. Respiratory symptoms and pulmonary function of traffic policemen in Thonburi. J Med Assoc Thai. 1999; 82(5): 435-43.
39. Jung H, Kim J, Lee S, Lee J, Kim J, Tsai P, et al. Comparison of filtration efficiency and pressure drop in anti-yellow sand masks, quarantine masks, medical masks, general masks, and handkerchiefs. Aerosol and Air Quality Research. 2014; 14(3): 991-1002.

40. Basavaraju K TK, Vivek P, Arifuddin MK, Kavitha BS. A Study of Effect of Air Pollution on Peak Expiratory Flow Rate in Traffic Police Men with and without Breathing Masks. Res J Pharm Biol Chem Sci. 2014; 5(5): 243-6.

41. Pure Living. Why 3M N95 Anti-Pollution Face Masks? What is the "right-fit" for you? [Online]. 2013. [Cited 2015 Nov 7]. Available from: http://www.purelivingchina.com/2013/02/why-3m-n95-antipollution-face-masks-what-is-the-right-fit-for-you/.

42. Sbihi H. Evidence on the use of masks as a public health intervention. In: Elliott C, Rideout K, ed. Evidence Review: Using masks to protect public health during wildfire smoke events. Vancouver: Environmental Health Services; 2014. p. 8-9. 